\title{
TERREMOTOS E IDENTIDAD CHILENA EN LA LETRA NERUDIANA
}

\author{
Luis Rubilar Solís \\ Universidad Metropolitana de Ciencias de la Educación \\ luis.rubilar@umce.cl
}

RESUMEN / ABSTRACT

Dada la consistencia geofísica del angosto territorio chileno extendido entre volcanes y placas tectónicas, la ocurrencia de catástrofes naturales ha sido diacrónica en su bicentenaria existencia como nación. Tanto la tradición oral como la escrita han consignado esta impronta telúrica como ingrediente ancestral de la identidad nacional. En la circunstancia vital del poeta Pablo Neruda (1904-1973) acontecieron cuatro terremotos cuyas semióticas réplicas resuenan en sus escritos. La voz del poeta advirtiendo este singular sino telúrico de esta finis terrae nos induce a evitar la mecánica amnesia colectiva y nos alerta para instituir en el imaginario social las necesarias actitudes de prevención frente a los desastres que inevitablemente nos deparará el futuro.

Palabras Clave: terremotos, telurismo, identidad nacional, Pablo Neruda.

Given the geo-physic consistency of the narrow Chilean territory, extended between volcanoes and tectonic plates, the occurrence of natural catastrophes has been diachronic in its bicentennial existence as a nation. The oral as well as the written traditions have expressed this seismic nature as an ancestral ingredient of national identity. In Neruda's vital circumstances (1904-1973) four earthquakes took place, whose semiotic aftershocks resound in his writing. Noticing the telluric fate in this finis terrae, the poet's voice invites us to avoid mechanical and collective forgetfulness, warning us to install in the social imagination preventive attitudes to face futures disasters.

KEY WORDS: Earthquake, seismic, national identity, Pablo Neruda. 
Oh patria terrible, en el centro de los terremotos...” (Neruda, 1967)

\section{I.- LA VULNERABLE EXISTENCIA DEL HOMBRE SOBRE LA TIERRA}

"El hombre es una cuerda tendida sobre el abismo. Es peligroso pasar al otro lado, peligroso permanecer en el camino, peligroso mirar hacia atrás; peligroso pararse y peligroso temblar" (Así hablaba Zaratustra, Nietzsche).

No cabe duda de que una dimensión fundamental para la construcción identitaria de una región o país la constituye su espacio terrestre, en tanto soporte material y entorno ambiental, con los factores bióticos y abióticos que la conforman. En este marco-continente, la tierra como enclave, cobijo y piso de sostén significa, además, un escenario pletórico de señales y orientaciones para nuestra existencia cotidiana, individual y social (Rubilar, "Vínculos"). El estatuto de la naturaleza y su biodiversidad imprime en la configuración subjetiva de sus huéspedes humanos anclajes primarios de índole afectiva y cognitiva, tal como lo expresa casi poéticamente Fidel Sepúlveda:

El territorio se revela en la imagen de la madre tierra. Esta es un segundo útero que nutre al habitante. Desde sus colores, líneas, ritmos, formas, modela los paisajes interiores del hombre. Desde los ruidos y sonidos del entorno le afina el oído para atender las voces de su ser. Los aromas, los sabores de frutos y frutas le transfieren la energía de sus raíces. El contacto de la piel del hombre con la piel del terruño troquela su autoctonía (45).

En este referente 'tierra' se encuentran sintetizados no solo aspectos de su endogenicidad sino también todos los referidos al universo y al cosmos como totalidad envolvente, por lo cual no se puede comprender su consistencia entitativa si no es desde una metodología 'compleja' (polifacética). "Como seres vivos de este planeta dependemos vitalmente de la biosfera terrestre", afirma Morin (Los siete 61).

La evolución filogenética muestra la interacción dialéctica e interdependencia de la existencia humana respecto al medio ambiente y al mundo externo. La indefensión y precariedad del hombre primitivo sumido en el sincretismo y el pensamiento mágico se irá superando a través de la construcción social de los procesos psicológicos superiores en lo personal (Vygotski), y del avance 
de la civilización y la cultura en lo colectivo. Las comunidades humanas, originariamente necesitadas y menesterosas, inmersas en hábitats inseguros y riesgosos, van imaginando e instituyendo formas de supervivencia y convivencia que les procuren, por sobre todo, 'territorios seguros'. Ortega y Gasset (Ideas y creencias) comprime bien esto a través de su postulado "yo soy yo y mis circunstancias", y de su aserto, "cultura es seguridad". A través del tiempo el control y dominio del hombre sobre la naturaleza se ha exacerbado generando consecuencias indeseadas, tal como estamos siendo testigos y víctimas a escala planetaria en el último tiempo ('calentamiento global' y 'contaminación/deterioro ambiental'), conduciendo inexorablemente a la pérdida de la conciencia ética (alienación) y a la amnesia colectiva respecto a su condición y origen.

Especialmente el devenir histórico amerindiano constituye un repertorio inmenso de cambios medioambientales y de catástrofes naturales, de impacto, a veces súbito, otras lento, desde cataclismos inmensos, pestes endémicas, sequías e inundaciones, deslizamientos, ciclones o huracanes, terremotos y tsunamis, erupciones volcánicas, incendios, huracanes, hambrunas, heladas y avalanchas, etc., en los cuales el actor protagónico respecto al índice de riesgo siempre ha sido el Hombre (García, Historia $y$ desastres). Paradójicamente las culturas originarias, por ejemplo en territorio andino, estuvieron mejor preparadas para afrontar los embates de fenómenos geofísicos extremos dada la calidad y ubicación de sus viviendas y comunidades ${ }^{1}$.

Los terremaremotos han significado en el pasado un especial tipo de calamidad y desastre que ha marcado con sus siempre catastróficos efectos el vínculo hombre-naturaleza. Movimientos sísmicos, eventos volcánicos, maremotos, en sus distintas magnitudes han acompañado desde siempre el habitar del hombre sobre la tierra, desestructurando los andamiajes técnicos y amenazando ese sentimiento de 'seguridad' que le otorgara el parapeto cultural, volviéndolo extremadamente 'vulnerable'. Es notable el aserto de Charles Darwin, testigo directo del terremoto de 1835 (Concepción-Valdivia):

1 Véase Calvo, Secretos y tradiciones mapuches; Fernández, Arica 1868: un tsunami y un terremoto; Lenz, "Tradiciones e ideas de los Araucanos acerca de los terremotos"; Mora, "Subir para ser: el camino de Chile y de las naciones andinas"; Vitale, Hacia una historia del ambiente en América Latina. 
Un terremoto fuerte destruye en un instante nuestras asociaciones más inveteradas; la tierra, verdadero emblema de solidez, se mueve bajo nuestros pies [...] un segundo de tiempo ha engendrado en el ánimo una extraña idea de inseguridad, que no hubieran producido horas de reflexión (70).

En este sentido, todo terremoto es numinoso, causa pánico, o literalmente 'terror', ese sentirse a-terrado, como se sintiera el aún desprotegido hombre primitivo.

Por eso, con razón dice Ortega: "Hay la creencia que la tierra es firme, a pesar de los terremotos que alguna vez y en la superficie de algunos lugares acontecen" (32). Los colapsos sísmicos nos retrotraen regresiva y dramáticamente a los orígenes del homo sapiens, de aquí la pérdida de los controles cognitivos y la regresión hacia primarias reacciones emocionales (indefensión, miedo, menesterosidad, angustia, egocentrismo, etc.).

Es ilustrativo mostrar cómo la perspicacia de un escritor, en este caso, del chileno Augusto D'Halmar, recapitula en un texto referido al terremoto del Valparaíso (1906) algunas recurrentes facetas antes aquí consignadas:

Vivimos confiados sobre la tierra; sin embargo, ella misma nos atrae de mala manera para hacernos perder el equilibrio o su equivalente interno: el control, y un traspié basta a dar duramente y de narices contra esta madre convertida en madrastra; un descuido, el más mínimo, y corre riesgo nuestra integridad personal [...] pánico ancestral insuperable [...]. Buscando socorro y refugio en el regazo humano [...]. Era como el fin del mundo [...]. La Naturaleza, con mayúscula, se sobreponía una vez más a la civilización artificial [...]. $\mathrm{Y}$ un pensamiento generoso, cumplido ya el egoísmo individual de salvarse, fue hacia tantos cuantos formaban parte de la familia chilena, empezando, naturalmente, por la de cada cual (299-303).

Para conocer el fenómeno 'terremoto' en forma cabal en tanto realidad polifacética, se requiere un correlativo abordaje a través de la metodología de la 'complejidad' (Morin, Introducción), que nos permita develar su significación como síntesis y punto de encuentro entre lo natural y lo humano. Tal comprensión abarcadora y unificadora convoca a la interdisciplina, al ejercicio de complementarias aproximaciones epistemológicas, incluyendo las artes y la literatura. 


\section{II.- CHILE, UN BORDE EN MOVIMIENTO}

"La Cordillera $[\ldots]$ de pronto se acuerda de su vieja danza de ménade y salta y gira con nosotros a su espalda" (Gabriela Mistral 1934).

El desencadenamiento de acontecimientos naturales o siniestros que han afectado las condiciones geoecológicas, climáticas y atmosféricas del territorio chileno van desde cataclismos y movimientos telúricos (sobre 125 sismos notables, desde 1570), gatillados por el choque entre placas tectónicas o erupciones volcánicas generadas por su ubicación en el 'círculo (cinturón) de fuego del Pacífico' (al menos 50, en particular de los volcanes Llaima, Villarrica, Antuco, Chillán o Calbuco), hasta los cambios pluviométricos y de temperatura provocados por los fenómenos oceánicos de El Niño y de La Niña. Tales devastadores eventos geológicos han acompañado y contaminado los desastres humanos y culturales acaecidos durante los casi quinientos años de su descubrimiento para el mundo europeo, conformando un territorio en crónica situación de vulnerabilidad y riesgo, y por lo mismo, comunidades altamente resilientes. En el ámbito geológico, los periódicos choques entre las placas tectónicas continentales Sudamericana y Nazca han ido cambiando su 'loca geografía', delineando sus relieves submarinos, sus bordes costeros y paisajes, y configurando aspectos básicos de su ethos cultural y del carácter social de sus habitantes. Desde mitos originarios, como la pugna entre la tierra y el agua $^{2}$-el ofídico mito mapuche del diluvio- se ha asentado en el imaginario chileno el sino de inevitables eventos geofísicos, que tras fallidos intentos amnésicos la propia tierra se encarga de recordar, como reciclando el mito del eterno retorno. Tal condición ancestral telúrica es reafirmada por la sabia opinión del preclaro profesor de Lingüística del Instituto Pedagógico, don Rodolfo Lenz:

Tales maremotos en los pocos siglos que conocemos de la historia de Chile se han observado repetidas veces, generalmente en unión íntima con terremotos coexistentes. Es seguro que también en siglos pasados han sorprendido al habitante de la costa chilena i que para él deben haber sido los fenómenos más terribles que puedan imaginarse (15).

2 Véase Manns, Los terremotos chilenos; Mora, "Subir para ser: el camino de Chile y de las naciones andinas". 
Consciente de tal herencia ancestral Pablo Neruda la asumirá replicando al sismo de 1960: "tocó la campana la lengua del antepasado en mi boca" (Obras III, 102).

\section{III.- EL ESPACIO TERRESTRE EN CANTO GENERAL (1950)}

"Neruda...desciende a las profundidades de la tierra y del océano a sentir la materia en el acto del génesis" (Alegría, Prólogo a Canto general, 1950)

\section{El territorio del habitante de esta FinIS TerRaE}

Para los originarios tanto incaicos como mapuches la tierra es madre: Pachamama o MAPU. Ellos vivieron y viven coalescentemente sus espacios, respetando los designios de la naturaleza y ubicando adecuadamente poblaciones y viviendas en prevención de fenómenos telúricos; construían el territorio como referente basal de sus prácticas culturales: su propio 'lugar'.

La percepción e impacto que la tierra amerindiana produce en sus habitantes posteriores, desde los escribidores Alonso de Ercilla o Alonso de Ovalle, hasta sus poetas más representativos, es singular y distintiva, siempre 'telúrica': un espacio demarcado, señalizador de identidades, nunca 'desterritorializado'.

Veamos lo que dicen de la 'tierra' dos poetas nuestros: parcamente Vicente Huidobro la llama "matriz formidable y oscura" e identifica a su creado Altazor: "Soy un temblor de tierra. Los sismógrafos señalan mi paso por el mundo" (O.C. I, 393), y más latamente Gabriela del Elqui dice de la suya: "La Cordillera, terriblemente dueña de nosotros, verdadera matriz chilena, vivimos y nos morimos dentro de su puño señor [...] hogar puro de fuego en unos volcanes adormecidos, que no dormidos [...]" (Cit. en Quezada 155). Agregando luego, "y lleva vivos y lleva muertos / el tambor indio de la Tierra" (174). El viajero y escritor francés André Bellessort (1897) connota este especial arraigo e impacto geocultural nuestro: "Los chilenos, encerrados entre la cordillera y el océano [...] debieron aprender temprano a valerse por sí mismos [...]. Una naturaleza áspera y salvaje [...] es a veces para un pueblo una excelente educadora" (159).

Por su parte, Mariano Picón-Salas, el insigne exiliado venezolano, apuntará en su Intuición de Chile (1933): "La geología, el paisaje, la tierra, son ahora como nunca los símbolos e imágenes de la verdadera alma chilena” (602). 
Pero la voz que mejor dirá la significación de la tierra en nuestra idiosincrasia continental y chilena será precisamente la de Pablo Neruda, en particular la que resuena en su Canto general, en cuyos inicios retumba lo telúrico y lo vernáculo como 'lámpara en la tierra' ${ }^{3}$.

La cosmogonía indígena mostrando el entramado y urdimbre existente entre sus habitantes y la configuración del espacio físico entre los originarios y su "madre-tierra", fue vivenciada directamente por el niño Neftalí en su infancia sureña. La tierra trepidante, los peligros y las ruinas, en especial para los pobres, la vivió en Temuco, y así rescata sus vivencias en "Infancia y poesía" (1954): "Luego venían las inundaciones, que se llevaban las poblaciones donde vivía la gente más pobre, junto al río. También la tierra se sacudía, temblorosa. Otras veces en la cordillera asomaba un penacho de luz terrible: el volcán Llaima despertaba" (O.C. IV, 920). El transfigurado poeta Neruda recogerá más tarde en su letra el impacto telúrico causado por desastres y cataclismos ligados a los cuatro elementos físicos: tierra (terremotos), aire (vientos y temporales), agua (maremotos e inundaciones) y fuego (erupciones volcánicas).

El Canto se inicia por lo geofísico y ecológico, lo vegetal y lo animal, primero la materialidad terráquea y solar que hace posible la vida, soporte y anclaje previo desde el cual es viable la creación y construcción del hombre y su cultura, con sus territorios y sus propias prácticas de vida y convivencia.

Aquí se enclava el enunciado-clave: "El hombre tierra fue... Tierra mía sin nombre, sin América" (Neruda, Canto general 3). Las primeras letras nerudianas contando y cantando Nuestra América están escritas, entonces, desde la tierra, con su roca-madre, sus aguas fluviales y volcanes, rescatando junto con ella los olvidados orígenes del 'padre mío', del indígena ligado simbióticamente con su entorno. Y allí en los confines, el principio de Chile: "en el fondo de América sin nombre/ estaba Arauco entre las aguas (Canto general 17), con sus árboles, pumas y piedras. Así expresaba cabalmente el poeta con su letra la primaria condición terrestre de Chile y de sus habitantes primigenios. En su poesía y en su prosa posterior reverbera insistente esta protomotivación terráquea en sus diversas manifestaciones: tierra misma,

3 Ver Rubilar, "Vínculos espaciales del constructo identitario latinoamericano: antecedentes literarios" y Psicobiografía de Pablo Neruda. 
cordillera, mar, océano, espacio, madera, piedra, destierro, erupciones, cataclismos, en fin, flora y fauna de su tierra amerindiana y chilena.

En el penúltimo 'canto' (XIV- El gran océano, 1948) ya avanza descubriendo el ala espantosa del pétalo patrio, a través de los estropicios y daños que las aguas marinas desatan, devastando la chilena tierra:

No es la última ola con su salado peso /la que tritura costas/

De los cuerpos / del hombre en tus orillas una húmeda/ fragancia / de flor mojada permanece..../ Sólo entregas despojos triturados.../ Y tembló para siempre en las orillas / La voz del mar, los tálamos del agua, La huracanada piel derribadora / La leche embravecida de la estrella (311).

Pero hay una manifestación privilegiada y peraltada de lo terrestre, encarnada en el propio ser humano, y que el poeta no atribuye al hombre abstracto sino -lo que es crucial-a sí mismo, en tanto 'residente' e 'incásico del légamo': "Yo estoy hecho de tierra" (Obras II, 846).

El crítico y poeta argentino Saúl Yurkiévich visualiza bien la presencia y acción matricial que la tierra significa en el espesor de su construcción poética, el arquetipo junguiano, casi consciente: "La tierra será siempre para Neruda la engendradora, la que da origen y alimento, la generadora, la regeneradora de la vida, su carnadura. La tierra patria sobre todo [...] madre y morada [...] América es 'útero verde', 'sabana germinal, bodega espesa' [...]” (145).

\section{IV.- LAS RÉPLICAS SEMIÓTICAS DE LOS TERREMOTOS CHILENOS}

\footnotetext{
"A través de toda la historia de la literatura y del folklore chileno -desde los cronistas hasta Neruda- se advierte el influjo de la naturaleza de Chile y la conciencia de su peculiaridad...” (Hernán Godoy, El carácter chileno 1976).
}

En el amplio marco referencial del 'espacio' y sus connotaciones territoriales específicas, para el caso chileno una de las conmociones más desestructurantes del paisaje externo e interno de su habitante ha sido y sigue siendo la pertinaz ocurrencia de terremotos en diversas regiones del país.

Antes fueron muchos y variados los relatos y testimonios referidos a esta crónica sismicidad chilena, a sus eventos telúricos casi consuetudinarios. Entre ellos, cronistas: Jerónimo de Vivar, Alonso de Góngora, Pedro Mariño, Diego de Rosales, Juan Ignacio Molina; viajeros: María Graham, Charles 
Darwin, Simón Rodríguez, Meter Schmidtmeyer; historiadores: Alonso de Ovalle, Miguel de Olivares, Felipe Gómez de Vidaurre, Miguel Luis Amunátegui, Diego Barros Arana, Benjamín Vicuña Mackenna, Francisco Encina, Rolando Mellafe, Manuel Fernández; Escritores/Artistas: Violeta Parra, Roberto Parra, Patricio Manns, Schwenke y Nilo, Augusto D'Halmar, Carlos Pezoa, Fernando Alegría, José Donoso, Poli Délano, Germán Marín, Isabel Allende, Alberto Fuguet, entre otros.

Aquí mostraremos algunos trepidantes reportes escritos:

Eugenio de Robiano (viajero belga, 1882):

Los temblores son periódicos en Chile [...] a veces terribles y fecundos en accidentes de toda especie o en verdaderos desastres [...]. El Océano Pacífico es a su vez a menudo sacudido violentamente por los sismos y las erupciones de volcanes submarinos [...]. Un día, en Valparaíso mismo, asistí a uno de estos sorprendentes espectáculos de la naturaleza. El mar, hasta entonces tranquilo e impasible, se puso bruscamente a hervir [...] se levantaron las aguas, las olas mugieron, espumaron $[\ldots]$ se la vio avanzar rápida, impetuosa, alcanzando las aguas del puerto [...] barre las calles bajas de la ciudad, entrando en las casas o invadiendo los sótanos (156 y ss.).

Joaquín Edwards (1961):

Me encuentro en Valparaíso. Mi llegada coincidió con salvas de cañones subterráneos, anuncios de 42 temblores. Hubo 57 temblores en dos días [....]. Tiembla todo el tiempo, He oído hablar de lo que sería un maremoto. El mar se tragaría la ciudad. Viña del Mar sería recuperada por el océano. Los peces pasarían por encima del Casino. Ha temblado otra vez. Veo en la pared de la pieza donde vivo una gran rajadura vertical. Es como advertencia de trépense: Morir habemos [...] (21).

Benjamín Subercaseaux (1940):

El país de la tierra inquieta... los terremotos son una experiencia extraña $[\ldots]$ imposible imaginar sin haberlas vivido [...]. Es la catástrofe inesperada por excelencia [...] el gran cataclismo viene súbitamente. En eso están su horror y su magnificencia [...]. Esta onda callada de pavor y desaliento distingue a los terremotos de los demás accidentes: desde el primer momento se produce una como 
debilidad en las piernas: un agolparse de la emoción en oleadas sucesivas que nos llevan el corazón a la boca y la angustia a todo el ser [...]. Todo ese mundo inerte, mudo; ese mundo que ha tenido por misión permanecer fijo y callado durante una existencia entera, adquiere de pronto una vida formidable [...] frente al hombre que ahora se queda clavado, sin atinar con lo que debe hacer [...] no hay espíritu crítico, estamos casi a ciegas [...]. El pánico y la gritería son indescriptibles [...] un horrible abandono nos trae a la realidad y nos desata el llanto (182 y ss.).

Hernán Godoy:

Pero el territorio de Chile no ha sido una madre pacífica, exuberante $\mathrm{y}$ tranquila, sino por el contrario pródiga en desastres. Terremotos y maremotos, inundaciones y sequías [...] hacen del nuestro 'un país de bella naturaleza que muere en convulsiones', es decir una madre difícil, maestra de energía (71).

Fernando Alegría:

Entre nieve y mar, con toda el alma, nos damos contra un rumbo ya tapiado,/ por consecuencia, en la mañana cuando Dios nos desconoce,/ cuando alzado a medianoche nos sacude un terremoto,/ cuando el mar saquea nuestras casas y se esconde entre los bosques,/ cuando Chile ya no puede estar seguro de sus mapas/ y cantamos, como un gallo que ha de picar el sol en pedazos,/ digo, con firmeza, ¡VIVA CHILE MIERDA! (Viva Chile, mierda!)

Estos correlatos semióticos, tan variados y heterogéneos son, sin embargo, concordantes en la atribución relevante que se otorga a los terremotos en la fisonomía identitaria de la geocultura de la nación chilena y de sus habitantes.

\section{V.- LAS RÉPLICAS NERUDIANAS}

"Tierra, pueblo y poesía son una misma entidad encadenada por subterráneos misteriosos" (Pablo Neruda, "Viaje al corazón de Quevedo", 1955).

Será otra vez el poeta Pablo Neruda quien acoja, asuma y exprese, a su manera, la persistencia del sino telúrico de la nación chilena, el cual con 
porfiada periodicidad viene recayendo sobre su pueblo, afectando duramente su patrimonio material y humano. A él le convino como destino contener y retener dichas experiencias, particularmente los eventos sísmicos ligados a su propio ciclo vital (1904-1973), es decir, los terremotos de Valparaíso (1906), Chillán (1939), Valdivia (1960), y en menor grado, La Ligua (1965), que tanto dolieran a su tierra, ese "largo pétalo, de mar, y vino y nieve" (Obras I, 846), ese delicado pétalo tocado por lo 'terrible'.

Matilde misma, su definitiva compañera, aparece como medusa enredada en la sismicidad: "Mi mujer es provinciana como yo. Nació en una ciudad del sur, Chillán, famosa en lo feliz por su cerámica campesina y en la desdicha, por sus terribles terremotos" (Neruda, Confieso 380). Él mismo nació en Parral, en plena actual Región del Maule, vecina a Chillán, zona privilegiada por sus permanentes remezones terrestres.

Para espigar su producción sísmica estableceremos cuatro hitos críticos demarcados por eventos a los cuales su pluma nos refiere directa o indirectamente, en la mayoría de los cuales paradójicamente no fue testigo directo.

a) 1906 (Valparaíso, $8.6^{\circ}$, con tsunami). De este impactante terremoto, Neftalí Reyes, niño huérfano en el campo parralino (Belén) no tuvo conciencia, solo referencias. Desde ellas menciona que su personaje 'Joaquín Murieta' sería chileno, ya que perdió sus documentos de identidad en ese terremoto y en las contiendas del oro (1967). Para él, y otros escritores, Valparaíso estará siempre marcado por ese y otros sismos; de aquí que en "Oda a Valparaíso" (1954) le dice: "te agarró el terremoto/...se movieron las aguas y las piedras.../ recibiendo/...el beso/ del ancho mar colérico/ que con toda su fuerza/ golpeándose en tu piedra/ no pudo/ derribarte... resisten/ las olas de la tierra" (Obras II, 192 y ss.).

Al rememorar sus propias andanzas juveniles por el puerto cuando estudiante del Pedagógico, en sus Memorias dice:

Valparaíso a veces se sacude como una ballena herida. Tambalea en el aire, agoniza, muere y resucita... Aquí cada ciudadano lleva en sí un recuerdo de terremoto. Es un pétalo de espanto que vive adherido al corazón de la ciudad... hay ese descalabro, ese estremecerse de la tierra que tiembla...A veces... salió del mar, como el último espanto, la gran ola, la inmensa mano verde que, alta y amenazante, sube como una torre de venganza barriendo la vida que quedaba a su alcance... El alma entre sueños se comunica con profundas raíces, con su hondura terrestre... Este es un pavor cósmico, una instantánea inseguridad, 
el universo que se desploma y se deshace. Y mientras tanto suena la tierra con un sordo trueno... Y nos quedamos solos con nuestros muertos y con todos los muertos, sin saber por qué seguimos vivos (Confieso 87).

b) 1939 (Chillán, $8.3^{\circ}, 30$ mil muertos). Acontece esta terrible catástrofe, recién asumido el presidente Pedro Aguirre Cerda, en tanto Neruda se prepara para ayudar a los españoles republicanos, y viaja pronto a Francia para organizar la histórica venida a Chile del Winnipeg. Ha comenzado en 1938 su "Canto de Chile", inicio de su magno Canto general, en el cual ya consigna la inveterada presencia sísmica:

Los pobres viven abajo esperando que el río /se levante en la noche y se los lleva el mar ("Inundaciones"); [...] Desperté cuando la tierra de los sueños faltó bajo mi /cama./ [...] Dame la mano en esta ruptura ciega del planeta/ [...] Por qué hierve la tierra llenándose de muerte?/ [...] sonrisas que no alcanzaron el espanto, seres despedazados/ bajo las vigas, cubiertos por la noche [...] buscando el rostro perdido de los insepultos ("Terremoto") (207).

Una inusitada réplica artística, gestada por la acción del poeta (Cónsul en México) fue la venida a la donada Escuela México en Chillán de los muralistas aztecas David Alfaro Siqueiros y Xavier Guerrero (1942), quienes dejaron en las paredes escolares sus geniales obras: Muerte al invasor y De México a Chile, respectivamente, y declarada Monumento Histórico nacional (2004).

c) 1960 (Valdivia, 9.5 , con tsunami y emergencia del río Riñihue. El de mayor magnitud en el mundo hasta ahora). Cuando sucede esta calamidad en el sur chileno, el poeta recién había viajado a Europa. La noticia lo encuentra en Paris, motivando su producción "Cataclismo", editada primeramente para ayudar a los damnificados y a la reconstrucción en Chile:

La noche de mil noches y una noche,/ la sombra de mil sombras y un latido,/ el agua de mil aguas que cayeron/ el fuego destapando sus embudos,/ la ceniza vestida de medusa,/ la tierra dando un grito.../ Yo soy el sumergido de aquellas latitudes/...allí donde yo pasé se sacudió la tierra/... Adentro está el terror, abajo duerme el terror/... El miedo envuelve los huesos como una nueva piel / envuelve la sangre con la piel de la noche, / bajo la planta de los pies se mueve la tierra: /... se desploma / otra vez la ciudad:.... / nuestro deber es 
abrir las manos y los ojos / y salir a contar lo que muere y lo que nace /... construyamos el muro, la puerta, la ciudad / comencemos de nuevo el amor y el acero / fundemos otra vez la patria temblorosa (Obras II, 947 y ss.).

Pero su producción más sentida y comprometida se encuentra en "Terremoto en Chile", ubicada en los comienzos de La barcarola (1967):

Allí, (en) Europa, supimos, amada, que Chile sufría quebrado por un terremoto.

Dios mío, tocó la campana la lengua del antepasado en mi boca, otra vez, otra vez el caballo iracundo patea el planeta y escoge la patria delgada, la orilla del páramo andino, la tierra que dio en su angostura la uva celeste y el cobre absoluto, otra vez, otra vez la herradura en el rostro de la pobre familia que nace y padece otra vez espanto y la grieta, el suelo que aparta los pies y divide el volumen del alma hasta hacerla un pañuelo, un puñado de polvo, un gemido. Por los muros caídos, el llanto en el triste hospital, por las calles cubiertas de escombros y miedo, $/ \ldots$ por el ave que vuela sin árbol y el perro que aúlla sin ojos, patria de agua y de vino, hija y madre de mi alma, déjame confundirme contigo en el viento y el llanto y que el mismo iracundo destino aniquile mi cuerpo y mi tierra./... Ay canta guitarra del Sur en la lluvia.../ y que tu canción me devuelva la patria en peligro.../ sí cantas, oh patria terrible, en el centro de los terremotos...

(Obras III, 102 y ss.).

d) 1965 (La Ligua, $7.6^{\circ}$ ). Tras este sismo, al volver de otro viaje a Europa, encuentra su casa porteña (La Sebastiana) toda removida, escribiendo en sus Memorias estas impresiones:

Hace dos días volví a entrar, después de una larga ausencia, a mi casa de Valparaíso. Grandes grietas herían las paredes. Los cristales hechos añicos formaban un doloroso tapiz sobre el piso de las habitaciones. Los relojes, también desde el suelo, marcaban tercamente la hora del terremoto. Cuántas cosas bellas ahora barridas con una escoba; cuántos objetos raros que la sacudida de la tierra transformó en basura (Confieso 379). 
En Fin del mundo recicla y resume estos obstáculos naturales que bañan las riberas costeñas del Océano Pacífico (1968): "La marejada se llevó/ todos los cercos de la orilla... / oh, marejada del rencor, / dije, mirando la hermosura/ de todo el mar desordenado/ en una batalla campal / contra mi patria sacudida / por un temblor inexorable/ y los designios de la espuma" (Obras III, 369).

Finalmente, ya en su póstumo El corazón amarillo (1974), en "Desastres", reitera los daños colaterales sísmicos en el país y en el puerto:

Cuando llegué a Curacautín/ estaba lloviendo ceniza/ por voluntad de los volcanes... / (más tarde) En Valparaíso caían/ alrededor de mí las casas/y desayuné en los escombros/ de mi perdida biblioteca/ entre un Baudelaire sobrevivo/ y un Cervantes desmantelado" (O.C. III, 797).

\section{VI.- BREVES CONCLUSIONES EPICÉNTRICAS}

Resulta reiterativa y connotativa la atribución asignada a la tierra como 'matricial' en el proceso de configuración del ethos cultural de los países andinos, en particular en el caso de Chile, como relevan sus grandes poetas: Huidobro, Mistral y Neruda.

El Canto general nerudiano constituye una crónica poética de la América, vertebrada de comienzo a fin por la presencia genésica y nutritiva de lo terrestre como fundamento de su construcción como formación social-histórica.

La referencia semiótica a sismos y maremotos nacionales, el lado 'terrible' del espacio, ha sido tan crónica como su ocurrencia fenoménica, desde la oralitura mapuche hasta la letra a cargo de cronistas, viajeros, historiadores, literatos y artistas, desde el siglo XVI (1570).

La obra nerudiana ha retenido en su letra la ocurrencia y significación de los terremotos para el territorio y el pueblo chileno durante el siglo XX, en particular en relación con los terremotos de 1906 (Valparaíso), 1939 (Chillán), 1960 (Valdivia) y 1965 (La Ligua). La obra más relevante respecto al tema sísmico, referida al de 1960, fue La barcarola (1967).

Estos flagelos periódicos que tanto estrago y devastación han causado en ciudades, campos y costas marinas, sumían a las poblaciones afectadas en la precariedad y el duelo colectivo y, a la vez y dialécticamente, generaban actitudes compartidas de enfrentamiento reparatorio y preventivo, tales como la institucionalización de 'planes arquitectónicos y reguladores' (1906), 'zonas de catástrofe' (1965), Oficina Nacional de Emergencia (ONEMI, 
1960-1974). Sin embargo, tanto en el ámbito formal oficial como en el de la intersubjetividad comunitaria, nunca el país nacional ni sus regiones han estado debidamente preparados para tales eventuales emergencias.

Paralelamente, en las letras, a pesar del decir de Richter, ya un adagio popular: 'un terremoto nunca llega solo', en este dominio expresivo de acontecimientos a cargo de escritores no aparece como algo relevante la necesidad de anticipación, de prevención colectiva ni, menos, la de implementar medidas comunicacionales y educacionales para mitigar los efectos tangibles e intangibles que iterativamente han acarreado tales desastres, especialmente para los más pobres (v. Aguilera).

Sin embargo, esta polifacética textualidad testimonial y reflexiva referida a una dimensión tan decisiva para la comprensión de nuestras raíces geoculturales e identidad nacional, constituye un rico andamiaje informativo y de apoyo logístico para la formación cívica, endógena, ecológica y preventiva de los ciudadanos chilenos del siglo XXI.

En este sentido, el aporte que el poeta Pablo Neruda nos ha legado -como metamensaje-apunta precisamente a preservar una conciencia vigilante, en un territorio construido como un lugar de permanencia y pertenencia colectiva, adornado siempre por la belleza de sus paisajes, y a veces por lo terrible de sus manifestaciones telúricas.

\section{VII.- BIBLIOGRAFÍA}

Aguilera, Silvia (coord.). El terremoto social del Bicentenario. Santiago: LOM, 2010.

Alegría, Fernando. Viva Chile, mierda! Santiago: Universitaria, 1965. Edición discográfica, con la voz de Roberto Parada. 1968.

Bellessort, André. Joven América. París: Perrin et cie, 1897.

Briones, Hernán. El abate Juan Ignacio Molina y elegías a la ruina de Concepción. Santiago: Biblioteca Nacional, 1997.

Calvo, Mayo. Secretos y tradiciones mapuches. Santiago: Andrés Bello, 2001.

Darwin, Carlos. Diario del viaje de un naturalista alrededor del mundo. Tomo II. Madrid: Calpe, 1921.

Délano, Poli. Solo de saxo. México: Grijalbo, 1998.

D’Halmar, Augusto. Recuerdos olvidados. Santiago: Nascimento, 1975.

Edwards, Joaquín. Memorias de Valparaíso. Santiago: Zig-Zag, 1969.

Fernández, Manuel. Arica 1868: un tsunami y un terremoto. Santiago: Universidad de Tarapacá, 2007. 
Fuguet, Alberto. Las películas de mi vida. Santiago: Alfaguara, 2003.

García, Virginia (coord.). Historia y desastres en América Latina. Dos volúmenes. Bogotá: La Red-CIESAS, 1996-1997.

Godoy, Hernán. El carácter chileno. Santiago: Universitaria, 1991.

Gómez, Felipe. Terremotos en Chile (Historia de Chile, I). Santiago: Ercilla, 1889.

Graham, María. Diario de su residencia en Chile. Santiago: Imp. Cervantes, 1909.

Huidobro, Vicente. Obras completas. Vol I. Santiago: Andrés Bello, 1976.

Lenz, Rodolfo. "Tradiciones e ideas de los Araucanos acerca de los terremotos". Anales Universidad de Chile CCXXX (1912): 5-23. .

Manns, Patricio. Los terremotos chilenos. Santiago: Quimantú, 1972.

Marín, Germán. Idola. Santiago: De Bolsillo, 2008.

Mistral, Gabriela. Antología. Santiago: Alfaguara, 2010.

Mora, Ziley. "Subir para ser: el camino de Chile y de las naciones andinas". Revista Mundo Nuevo. Julio 2010. http://www.mundonuevo.cl/blog/articulos/el-secreto-indigena-delos-terremotos-chilenos/

Morin, Edgar. Los siete saberes necesarios para la educación del futuro. Barcelona: Paidós, 2001. Introducción al pensamiento complejo. Barcelona: Gedisa, 2007.

Neruda, Pablo. Canto general. 1950. Caracas: Ayacucho, 1976.

La Barcarola. Buenos Aires: Losada, 1967.

Confieso que he vivido. Barcelona: Seix Barral, 1974.

Obras. Tres vols. 1957. $5^{\text {a }}$ edición. Buenos Aires: Losada, 1993.

Obras completas. Tomos III-IV. Barcelona: Galaxia Gutenberg, 2000/2001.

Nietzsche, Federico. Así hablaba Zaratustra. México: Filosófica, 1956.

Ortega y Gasset, José. Ideas y creencias. Madrid: Espasa-Calpe, 1968.

Ovalle, Alonso de. Histórica relación del reino de Chile. Santiago: Universitaria, 1993.

Parra, Roberto. Poesía popular, cuecas choras y La Negra Ester. Santiago: FCE, 1996.

Picón-Salas, Mariano. Obras selectas. Caracas: Edime, 1962.

Quezada, Jaime. Gabriela Mistral. Nuestra América. Santiago: USACH, 2005.

Robiano, Eugenio de. Dieciocho meses en América del Sur (II Parte, 1882). Santiago: CoLibris, 2005.

Rodríguez, Simón. "Informe del terremoto de Concepción, 1835". Obras completas. Vol. I. Caracas: Universidad Simón Rodríguez, 1975. 471 y ss.

Rubilar, Luis. "Vínculos espaciales del constructo identitario latinoamericano: antecedentes literarios". Corredor de las Ideas. Integración y Globalización. Sâo Leopoldo, Brasil RS: Unisinos, 2000. 41-55.

Psicobiografía de Pablo Neruda. Santiago: USACH, 2003.

Sepúlveda, Fidel. "La identidad en la cultura tradicional”. Revista Universitaria 54 (1996): 45 y ss.

Subercaseaux, Benjamín. Chile, o una loca geografia. Santiago: Universitaria, 1973. 
Schmidtmeyer, Peter. Viaje a Chile a través de Los Andes. Buenos Aires: Claridad, 1947. Vygotski, Lev. El desarrollo de los procesos psicológicos superiores. Madrid: Crítica, 2003. Vitale, Luis. Hacia una historia del ambiente en América Latina. México: Nueva Imagen, 1983. Yurkiévich, Saúl. Fundadores de la nueva poesía latinoamericana. Barcelona: Seix Barral, 1971. 